\title{
Simulation of a regeneration plant for spent pickling solutions via spray roasting
}

\author{
D. Bascone ${ }^{a}$, A. Cipollina ${ }^{b}$, M. Morreale $^{a}$, S. Randazzo ${ }^{a}$. G. Micale $^{b}$ \\ ${ }^{a}$ Facoltà di Ingegneria e Architettura, Università degli Studi di Enna "Kore" - Cittadella Universitaria, \\ 94100 Enna, Italy. \\ ${ }^{b}$ Dipartimento di Ingegneria Chimica, Gestionale, Informatica, Meccanica, Università di Palermo - Viale \\ delle Scienze ed.6, 90128 Palermo, Italy. \\ "Corresponding Author. E-mail: marco.morreale@ unikore.it
}

\begin{abstract}
Nowadays, pyrohydrolysis techniques are widely applied for regeneration of spent pickling liquors providing an excellent environmental and economical strategy to the problem of waste disposal/recovery, also thanks to the high acid recovery efficiencies (>99\%) achieved ${ }^{1}$. In fact, in these processes, iron chlorides are converted into iron oxides and hydrogen chloride at high temperature in spray roasting or fluidized bed reactors ${ }^{2}$. Though the state-of-the-art technologies have been successfully applied only to large scale plants, the development of small scale units, able to perform a delocalized regeneration of spent solutions where these latter are actually produced, would be strongly needed in order to minimize the transportation of hazardous spent pickling and fresh $\mathrm{HCl}$ solutions to/from pickling factories from/to large centralized regeneration plants.

In the present work, a steady state simulation model for regeneration of spent pickling liquor via spray roasting has been developed, aiming at the analysis of performance of a small-scale unit. The simulation and optimization of the process has been carried out using ASPEN Plus simulator. A simplified model of the spray roaster, based on data collected from studies reported in the literature ${ }^{3}$, has been implemented and exported from ASPEN Custom Modeler.

Solid recovery from roaster off-gases has been obtained by a cyclone and a Venturi scrubber, where the spent pickling liquor is concentrated prior to be sprayed into the reactor. Hydrogen chloride is absorbed in an adiabatic absorber, where a sub-azeotropic $(18-20 \mathrm{wt} \%)$ hydrochloric solution is obtained. Prior to the stack, a scrubber is required to wash off the exhaust gases.

Several parametric studies have been performed. Different designs of solid separators have been compared in order to investigate the particulate separation efficiency of the process, while absorption column's packing types and rinse water flowrates have been varied in order to investigate their effects on $\mathrm{HCl}$ recovery and acid gas emissions.
\end{abstract}

\footnotetext{
${ }^{1}$ M. Regel-Rosocka, A review on methods of regeneration of spent pickling solutions from steel processing, Journal of Hazardous Material. 177 (2010) 57-69

${ }^{2}$ E.M.L.Peek, Chloride Pyrohydrolysis - Lixiviant Regeneration and Metal Separation, (1995)

${ }^{3}$ M. Schiemann, S. Wirtz, V. Scherer, F. Barhold, Spray roasting of iron chloride $\mathrm{FeCl}_{2}$ : Numerical modelling of industrial scale reactor, Powder Technology 245 (2013) 70-79
}

\section{Keywords}

Process simulation; pyrohydrolysis plant; hydrochloric acid regeneration. 